\title{
Sobre a pesquisa enquanto bricolagem, \\ reflexões sobre o pesquisador como bricoleur
}

Aline Nunes (UFG/GO) ${ }^{1}$

\begin{abstract}
Resumo
O texto proposto tem como intenção apresentar e problematizar os aspectos que compõem a bricolagem enquanto uma abordagem metodológica das ciências sociais, mais especificamente com foco nos processos de investigação em educação. A argumentação realizada a partir dos referenciais Denzin e Lincoln (2006) e Kincheloe e Berry (2007), se constrói ancorada em três pontos: uma apresentação do tema segundo seus conceitos; um exemplo no qual se utiliza tal abordagem e por fim, questões e dúvidas acerca de seus limites e contradições.
\end{abstract}

Palavras chave: bricolagem, processos de investigação, abordagem metodológica

\author{
About the research as bricolage, \\ reflections on the researcher as bricoleur
}

\begin{abstract}
The proposed of this text is to present and discuss the aspects that compose the bricolage as a methodological approach of the social sciences, more specifically focusing on the processes of research in education. The argument made from the reference Denzin; Lincoln (2006) and Kincheloe; Berry (2007), builds anchored at three points: a presentation of the subject according to its terms; an example in which this approach is used, and finally, questions and doubts about its limits and contradictions.
\end{abstract}

Key words: bricolage, research processes, methodological approach

\section{Parte 1: Separar as ferramentas}

Penso neste texto enquanto espaço de reflexão (movente, imprecisa, sem fins conclusivos), enquanto possibilidade de questionar, explicitar e até mesmo reconceituar concepções acerca da bricolagem durante meu percurso como investigadora (iniciante) no campo da arte, da educação e da cultura visual. Especialmente pelo fato de ter ampliado e posto em suspensão os modos de pensá-la e entendê-la, na medida em que tive a oportunidade de discutir esta perspectiva metodológica junto a outros 
pesquisadores/professores, igualmente interessados em compreendê-la em sua complexidade ${ }^{1}$.

Para tanto, o texto desenvolve-se num primeiro momento a partir das reflexões e diálogos que estabeleço com duas importantes referências no tocante à bricolagem, os autores Denzin e Lincoln (2006) e Joe Kincheloe e Kathleen Berry (2007). São eles que conceituam e trazem para o campo da pesquisa qualitativa e, mais especificamente para a pesquisa em educação, a bricolagem como abordagem metodológica.

No decorrer da escrita buscarei apontar as tensões que percebo no uso desta abordagem, e por fim, ampliar as possibilidades de pensar e operar com a bricolagem no âmbito da pesquisa acadêmica segundo os modos com os quais venho explorando-a.

\section{Estamos falando de quê??}

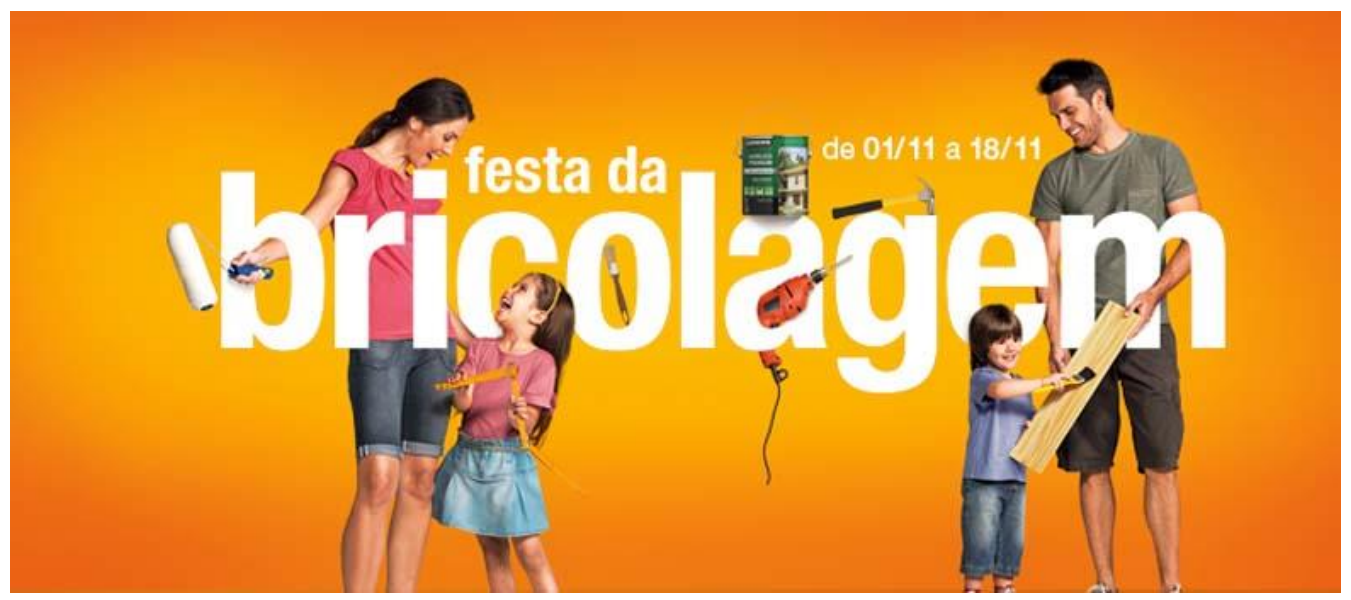

Figura.1. faça você mesmo! Fonte:

http://www.blogleroymerlin.com.br/2013/11/01/festa-da-bricolagem-2013-01-a-18-denovembro/

No meio acadêmico ainda é comum ouvirmos que a bricolagem é um apanhado de coisas: métodos, instrumentos e processos mesclados. Por vezes considerada sem nome e sistematização, usa-se o termo para definir algo que não se consegue explicar: um caminho de pesquisa marcado por um arranjo heterogêneo de procedimentos e (equivocadamente) tornando-se sinônimo de vale-tudo metodológico. Pontos estes que

\footnotetext{
1 Muitos destes momentos proporcionados pelos professores Irene Tourinho e Raimundo Martins e os colegas mestrandos e doutorandos do Programa de Pós-Graduação em Arte e Cultura Visual- FAV-UFG, durante o Seminário de Pesquisa em Arte, Educação e Visualidades, ocorrido no ano de 2011.

Revista Digital do LAV - Santa Maria - vol. 7, n.2, p. 30-41 - mai./ago.2014
}

ISSN 1983-7348 http://dx.doi.org/10.5902/1983734815112 
acabam sendo amplamente discutidos pelos autores/pesquisadores que se ocupam em estudar a bricolagem.

É gracioso, pois o uso deste termo não só é crescente em termos de investigação, mas em termos mercadológicos: há uma vasta gama de revistas que tratam o tema desde o ponto de vista da criação de artigos artesanais, e nas grandes lojas de departamento voltadas à casa e construção há sessões inteiras demarcadas por grandes letras: BRICOLAGEM. Piadas e surpresas à parte, revirando sites e fazendo buscas mais detalhadas sobre o tema percebo que temos algo em comum e que aproxima este tipo de "serviço" aos nossos interesses acadêmicos.

Não por acaso a bricolagem como método é vista como um emaranhado de possibilidades, o termo francês bricolage carrega consigo este sentido de improviso, de "faça você mesmo". A bricolagem em termos de investigação deve ser entendida como criação. Criação de um processo marcado pela experimentação, pelo uso/desuso de procedimentos, pelos achados e descartes de referências, de objetos de estudo, de perguntas e objetivos... Poderia dizer que esta condição de "fazer você mesmo" um modo próprio de pesquisar é o que empreende esta abordagem metodológica. $\mathrm{O}$ bricoleur metodológico bem como o bricoleur de fim de semana deve estar munido de um espírito construtor, catador de matérias e materiais que serão moldados, combinados e forjados com suas ferramentas, conforme sua intenção e necessidade.

Enquanto investigadores sabemos que apontar de antemão um tipo metodologia a ser utilizada pode supor um problema, na medida em que o pesquisador ainda está ensaiando de modo desajeitado seus interesses, adequando suas perguntas aos objetos de estudo e, em meio à isso depara-se com uma quantidade vasta de possibilidades teórico-metodológicas pelas quais pode sentir-se atraído. Falamos então de uma etapa do trabalho que exige de nós atenção para manter-nos reflexivos e vigilantes sobre nossas escolhas e sobre cada passo a ser dado, bem como atenção para sermos ousados nos momentos necessários, a fim de que a pesquisa avance.

Kincheloe traça alguns apontamentos a este respeito que podem ser mais elucidativos, em especial no caso do uso da bricolagem como abordagem metodológica

Os bricoleurs entendem que a interação dos pesquisadores com os objetos de suas investigações é sempre complicada, volátil, imprevisível e, certamente, complexa. Essas condições descartam a prática de planejar antecipadamente as estratégias de pesquisa. Em lugar desse tipo de racionalização do processo, os bricoleurs ingressam no ato de pesquisa como negociadores metodológicos. Sempre respeitando as demandas da tarefa que tem pela frente (...) $(2007$, p.17).

Revista Digital do LAV - Santa Maria - vol. 7, n.2, p. 30-41 - mai./ago.2014

ISSN 1983-7348 http://dx.doi.org/10.5902/1983734815112 
Aqui é possível retornar à ideia de que de algum modo somos também escolhidos pela metodologia, ao passo que os contornos metodológicos vão se dando durante o trabalho de campo do pesquisador. A pesquisa, sempre em processo de transformação, acontece em meio ao percurso e em meio ao tempo que temos para desenvolvê-la. Neste sentido uma vez mais partilho das ideias de Kincheloe (2007, p.19), quando diz que "a bricolagem subversiva aceita o fato de que a experiência humana é marcada por incertezas e que nem sempre a ordem é estabelecida com facilidade".

Por outro lado, convém retomar uma questão: embora não estejamos falando de um planejamento fechado é importante levarmos em conta a necessidade de algum tipo de organização ou de planejamento prévio, ainda que seja concebido como ensaio e trabalhado desde uma postura de flexibilidade.

A negociação pode ser pensada como um aspecto chave dentro do contexto da bricolagem, pois apresenta a necessidade de um pesquisador que se mantenha aberto, flexível e perceba que, em certos momentos, suas iniciativas de pesquisa devem ser repensadas, revistas, adaptadas. Nada é desde sempre nem para sempre, isto é, em se tratando de pesquisa há sempre a necessidade de parar para perceber o desenho que está sendo formado, uma vez que a pesquisa é movediça e, por isso, requer que a olhemos por diferentes ângulos. Todas as posturas e atos tomados estão sempre imbuídos de objetivos e nunca de neutralidade, por maior que seja nossa abertura ao desconhecido e ao inesperado no trabalho.

Outro ponto interessante sobre a bricolagem é que esta negociação se estabelece também internamente, entre os múltiplos tipos de bricoleurs que podemos ser e pelos quais podemos ser habitados. Para Denzin e Lincoln (2006), o bricoleur configura-se dentro de múltiplas modalidades, todas elas podendo ser vistas de modo separado ou, entrecruzado, coexistindo entre si e potencializando ainda mais o trabalho do pesquisador. Conforme os autores há cinco modalidades de bricoleur: o metodológico, o teórico, o interpretativo, o político e o narrativo. Destaco agora os pontos que considero mais esclarecedores, a partir dos apontamentos dos autores:

- O bricoleur metodológico é aquele que desenvolve múltiplas tarefas, estas especialmente de cunho procedimentais, isto é, quando o pesquisador transita e trabalha utilizando as mais diferentes estratégias metodológicas em seu trabalho, utilizando "desde uma entrevista até uma auto-reflexão e introspecção intensivas" (DENZIN e LINCOLN, 2006, p. 20). 
- O bricoleur teórico seria assim classificado devido ao alto investimento despendido a leituras, sendo considerado muito bem-informado quanto aos distintos paradigmas interpretativos (tais como estudos feministas, estudos culturais, teoria queer, pós-estruturalismo, construtivismo...). Ainda, o pesquisador como bricoleur teórico "trabalha dentro de perspectivas e paradigmas concorrentes e sobrepostos, e entre eles" (DENZIN e LINCOLN, 2006, p. 20), contudo estando atento aos desafios de construir argumentos plausíveis com relação à pertinência de tais articulações e hibridações conceituais.

- O bricoleur interpretativo estaria focado nas relações estabelecidas entre a pesquisa e as histórias de vida dos sujeitos envolvidos nos processos investigativos, compreendendo que a pesquisa é mediada por questões como gênero, classe social, biografia, fatores generacionais, entre outros aspectos sócioculturais que atuam fortemente nas construções de sentidos e visões de mundo (dele e demais sujeitos que integram o cenário em questão).

- O bricoleur político compreende que a produção de conhecimento está indissociavelmente ligada às relações de poder, uma vez que "todas as descobertas da pesquisa tem implicações políticas. Não existe nenhuma ciência livre de valores." (DENZIN e LINCOLN, 2006, p. 20).

- O bricoleur narrativo é aquele que está em sintonia com as questões próprias de seu tempo e contexto histórico, sem perder de vista seus imbricamentos com a questão de gênero. Deste modo tem clareza acerca de que os "pesquisadores contam histórias sobre os mundos que estudaram", e que estas narrativas são construídas dentro de espaços e "tradições específicas, muitas vezes definidas como paradigmas". (DENZIN e LINCOLN, 2006, p. 20).

É perceptível que todas estas categorias atribuídas aos pesquisadores bricoleurs não são estanques. No exercício de pensarmos sobre cada uma delas sentimos que elas se combinam, se confundem e por vezes se complementam, criando ligações entre si. A meu ver são justamente estas conexões que caracterizam a bricolagem, evidenciando e colocando como prioridade este estado de constante cambio, permuta e reposicionamento, tanto de si (pesquisador), quanto de seus focos de interesse investigativo.

Acredito que a relevância deste mapeamento realizado por Denzin e Lincoln (2006) está em compreendermos melhor como o processo de tornar-se um bricoleur acontece, não como um meio de encontrar uma definição completa e que encerre as problematizações 
em torno aos objetivos do bricoleur, mas sim, enquanto um modo de perceber as diferentes nuances com e por meio das quais o pesquisador vai performando-se, segundo suas inclinações e desejos.

Entendo as categorias sugeridas pelos autores como uma espécie de jogo, cujas peças serão combinadas e recombinadas por mim conforme a predisposição e interesse investigativo daquele que se interessa pelas orientações da bricolagem. A bricolagem é assim percebida em seu constante estado de desmanchamento de formas e modelos, de precariedade, no sentido de que já nasce de uma forma não concreta, adaptada, de um processo "que envolve construção, reconstrução, diagnóstico conceitual, negociação e readapatação" (KINCHELOE; BERRY, 2007, p.17)

\section{Bricolando noções de bricolagem}

Aqui o próprio texto no momento em que está sendo escrito se configura como uma bricolagem: as partes vão sendo produzidas e, no meio do processo são descartadas, sobrepostas, desencaixadas de modo a tentar compor algo que seja mais prazeroso ao leitor, a fim de que possa dar-Ihe alguma orientação sobre o tema. Sem dó nem piedade (ou quase...) descolo blocos inteiros, escritos durante tantos dias, esmigalho pedacinhos daquilo que em outro momento foi uma pesquisa... cato os fragmentos daquilo que ainda pode vir a ser um conjunto interessante.

Neste exercício de espigar ${ }^{2}$, de espreitar algo que possa ser útil neste contexto tão particular opto por trazer partes da minha experiência com a bricolagem durante a pesquisa que realizei no mestrado em educação ${ }^{3}$ e seus desdobramentos na pesquisa doutoral que desenvolvo atualmente.

Meu primeiro encontro com a bricolagem acontece no ano de 2008, quando no momento em que desenvolvia a pesquisa de mestrado fui atravessada por inúmeras abordagens metodológicas, tantas quantas podem ser as dúvidas de quem se insere no campo das pesquisas acadêmicas. Perdi a conta das vezes em que ouvi de meus professores que as escolhas metodológicas definem 'as lentes' com as quais produzimos, analisamos e interpretamos o material bruto de nossas investigações. Pensava comigo: para um

\footnotetext{
2 No sentido da palavra espanhola, em que espigar pode ser o mesmo que catar em diferentes fontes, consultar, esmiuçar e apropriar-se, segundo a conveniência, de alguns dados fragmentados.

3 Pesquisa de mestrado intitulada "Narrativas fílmicas e educação das artes visuais - percursos, afetos e bricolagens na formação inicial de professores", desenvolvida no Programa de Pós Graduação em Educação, linha de Educação e Artes, sob orientação da profa Dra. Marilda Oliveira de Oliveira e integralmente financiada pela Capes.

Revista Digital do LAV - Santa Maria - vol. 7, n.2, p. 30-41 - mai./ago.2014
}

ISSN 1983-7348 http://dx.doi.org/10.5902/1983734815112 
pesquisador iniciante é muito mais fácil saber o que a pesquisa não é, do que propriamente defini-la em seus parâmetros metodológicos, de modo acertivo.

Descobrindo diferentes instrumentos e enfoques, cheguei ao conhecido texto "O Planejamento da Pesquisa Qualitativa- teorias e abordagens", de Denzin e Lincoln (2006), que de um modo amplo tratava a pesquisa qualitativa como uma bricolagem, isto é, enquanto conformação de uma série de orientações e elementos distintos, não necessariamente idênticos em todas as pesquisas, e aos quais, por sua vez, o pesquisador pode recorrer conforme a necessidade percebida durante o trabalho de pesquisar. Segundo os autores o pesquisador como bricoleur seria aquele que extrai conteúdos de diferentes disciplinas, que produz colchas de retalhos a partir dos diferentes referenciais que Ihes são convenientes, num movimento contínuo de reflexão e produção de agenciamentos ${ }^{4}$.

Durante o período de mestrado trabalhei com a perspectiva da bricolagem desenvolvendo um projeto com referências nos princípios de duas abordagens: a Investigação Baseada em Artes (IBA) e a Investigação Narrativa. A partir desta mescla experimentei diferentes procedimentos, todos amparados pelo guarda-chuva teóricometodológico da bricolagem.

Como forma de conhecer os sentidos produzidos por professores em formação inicial a partir do contato com narrativas fílmicas lancei mão de alguns caminhos: os filmes como dispositivos que acionam o pensar; encontros sistematizados com professores para oportunizar o debate e o entrecruzamento de ideias; convites para a produção de imagens e narrativas visuais (vídeos, mapas, HQ's); roteiro de perguntas abertas; escrita de um diário de pesquisa... Vistos assim, com o devido distanciamento, podem ser pensados como exagero de principiante, por outro lado, para um pesquisador bricoleur são possibilidades.

Nem todos os procedimentos são usados com a mesma intensidade nos diferentes momentos do trabalho, nem todos são combinados e trabalhados com a mesma potência por mim e pelos professores. E este talvez tenha sido o ganho maior do trabalho: a possibilidade de experimentar, de propor convites, de correr o risco de perceber no meio do processo que nem todos os procedimentos lançados seriam bem recebidos, seriam "aproveitados ao máximo" ou do mesmo modo pelos professores. Lembrando as palavras de Denzin e Lincoln (2006), o bricoleur é um músico de jazz, que faz uso de suas

\footnotetext{
${ }^{4}$ Agenciamento conforme proposto por Deleuze e Guattari (1995), e aqui explicitado por Tomaz Tadeu da Silva:"o arranjo, a combinação de elementos heterogêneos, díspares, fazendo surgir algo novo, que não se pode resumir a nenhum dos elementos isolados que o compõem"

Revista Digital do LAV - Santa Maria - vol. 7, n.2, p. 30-41 - mai./ago.2014
}

ISSN 1983-7348 http://dx.doi.org/10.5902/1983734815112 
habilidades e conhecimentos para criar, para improvisar em suas composições, sem garantias.

Com o término da dissertação, muito ainda poderia ser estudado e explorado sobre e a partir do tema, em especial por ter me apropriado desta noção (desde o conceito cunhado por Kincheloe e Berry) no intuito de pensá-la também no que toca aos processos de constituir-se professor ${ }^{5}$ e investigador. Assim, minhas inquietações em torno à bricolagem continuaram latentes, seja com relação às questões metodológicas, seja nas relações que estabeleço com os modos de investigar ou com a formação de professores.

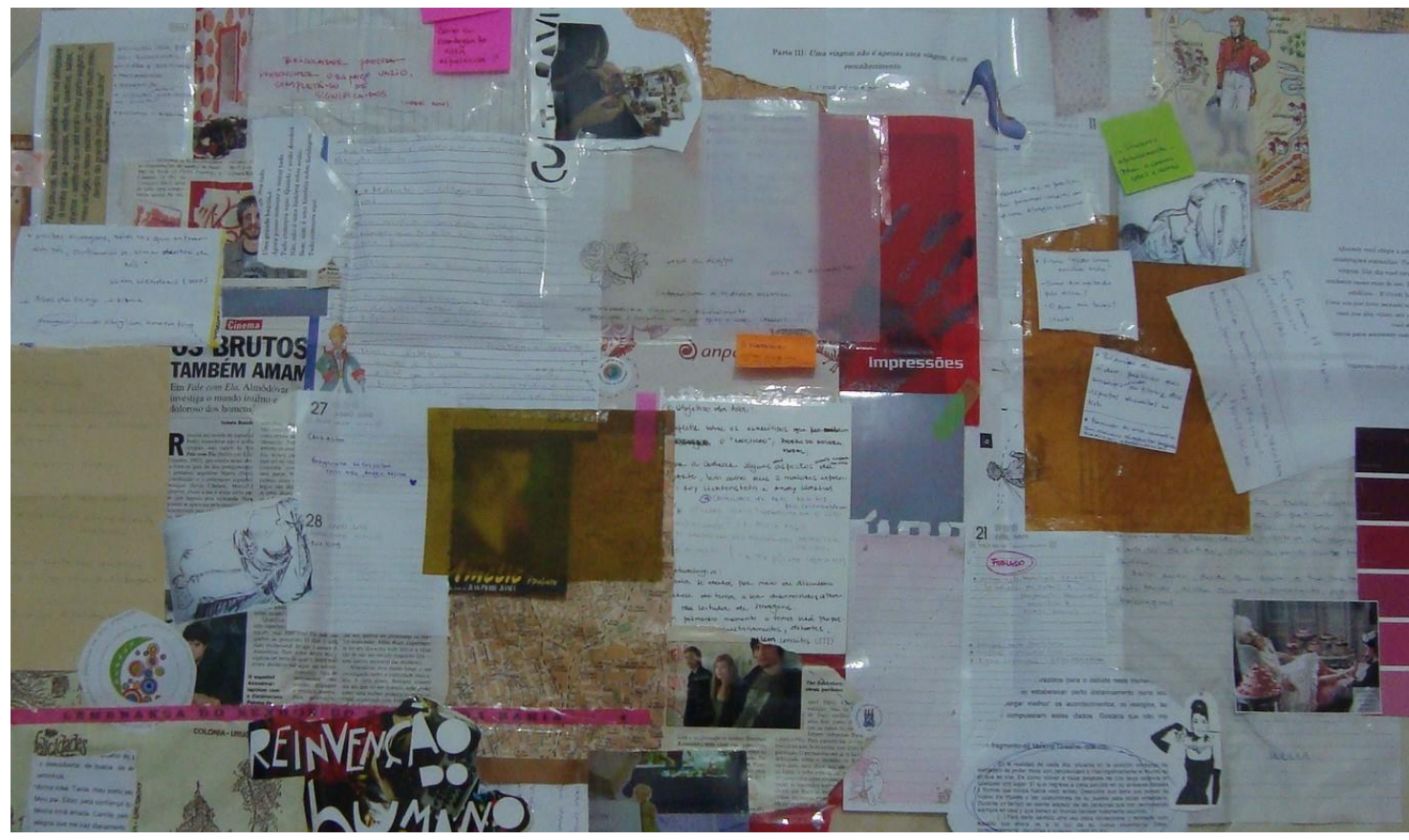

Figura.2. Vestígio de um bricolamento afetivo $(2010-2011)^{6}$. Fonte: Arquivo pessoal.

\section{Desestabilizando conceitos, suspendendo certezas}

\footnotetext{
${ }^{5}$ É possível conhecer mais sobre estas articulações em Nunes, 2011, no artigo intitulado "Notas sobre um professor bricoleur: inventando possíveis para pensar a formação inicial em artes visuais", publicado na Revista da FUNDARTE, edição de dezembro de 2011.

6 Partindo da intenção de produzir um mapa de interesses, ideias e referências, produzi o que chamo de bricolamento afetivo: bricolamento como percurso, como uma produção que se manteve em transformação contínua, sendo sobreposta e alterada por colagens que se deslocavam (eram fragilmente fixadas, extraídas, rasgadas...), criando uma composição, sem formato e contornos predefinidos (ainda que não se perceba pelo formato desta figura), que foi sendo produzida durante os meses posteriores ao término do trabalho de mestrado e os primeiros meses do ingresso no doutorado.
}

Revista Digital do LAV - Santa Maria - vol. 7, n.2, p. 30-41 - mai./ago.2014

ISSN 1983-7348 http://dx.doi.org/10.5902/1983734815112 
Em minha investigação atual, por ter escolhido diferentes caminhos, a bricolagem enquanto método acabou dissipando-se em meio a outras escolhas. Utilizando parte das noções com as quais trabalho na tese doutoral ${ }^{7}$, percebo que talvez ela tenha sido deslocada e reterritorializada em outras porções de minha vida acadêmica. Conforme mencionei ao longo do texto, entendo a bricolagem não só como forma de arranjar e orientar uma pesquisa ou um projeto de investigação: há nisto tudo um devir bricoleur.

Este é um estado em que, mesmo que se modifiquem os referenciais e perspectivas teóricas, mesmo quando os modos de produzir o trabalho sejam outros, nos colocamos à cata de novas formas a serem combinadas, mantemo-nos numa postura em que estamos abertos e, sobretudo, em estado permanente de alerta para que novas criações aconteçam e façam vazar outros modos de construir um trabalho acadêmico, numa tentativa constante de experimentar, evitando, sempre que possível, julgamentos e préconcepções sobre o que ainda desconhecemos.

A postura indagadora, tão cara aos bricoleurs (e a qualquer investigador) segue acompanhando-me: o que nos impulsiona a investigar? A quem interessa o que produzimos? Como produzir uma pesquisa que seja um convite (ainda que micro) ao pensamento? Como produzir um trabalho que, depois de finalizado, não fique inerte?

Também por esta postura assumida, no decorrer das explorações em torno ao tema da bricolagem em determinado momento embati-me com a noção de um pesquisador bricoleur que dá conta de tudo, "o super bricoleur": faz pesquisas, é "crítico reflexivo", participa e "aprende avidamente a partir de lutas sindicais" (KINCHELOE, 2007, p. 30), promovendo transformações sociais.

São questões pontuadas pelo autor em algumas passagens do texto que me provocam a pensar: pouco a pouco saímos de uma tradição de pesquisa em educação em que os modelos/métodos empregados garantiam um descortinamento do mundo, supostamente possibilitando a chegada do pesquisador a uma verdade (quase) universalizante. Por outro lado, ao propor novas possibilidades de entender a pesquisa, a bricolagem por vezes também me parece estar em busca de clarificar alguma situação obscura, 'dando voz e luz' aos contextos oprimidos e marginalizados. Seriam suas heranças ligadas às teorias críticas/pós-críticas? Tenho ressalvas sobre essa capacidade/responsabilidade atribuídas ao bricoleur (ou qualquer outro tipo de pesquisador), por considerá-la uma

\footnotetext{
7 Investigação doutoral realizada no Programa de Pós-Graduação em Arte e Cultura Visual, na Faculdade de Artes Visuais da Universidade Federal de Goiás, sob orientação da Profa Dra. Alice Fátima Martins e com financiamento integral CAPES. Nesta pesquisa busco conhecer e pensar sobre os processos de desterritorialização experimentados por estudantes de pós-graduação a partir de seus deslocamentos territoriais.

Revista Digital do LAV - Santa Maria - vol. 7, n.2, p. 30-41 - mai./ago.2014
}

ISSN 1983-7348 http://dx.doi.org/10.5902/1983734815112 
postura demasiadamente pretensiosa, de quem se coloca em posição vantajosa, de ser capaz de ver e conhecer algo ao qual os demais não tem alcance. Seria esta a aporia da bricolagem?

Porém não desconsidero uma importante ponderação de Kincheloe que é bastante elucidativo ao dizer-nos que

A bricolagem não entra nesta situação paradigmática como um cavaleiro montado em um cavalo branco, pronto para "salvar" o campo. Este tipo de bravata não é a razão para a construção da bricolagem. À luz das vicissitudes do atual estado da pesquisa social, cultural, psicológica e educacional, a bricolagem serve como uma forma de apontar e organizar impulsos existentes. Neste contexto, serve para promover entendimento e comunicação, e criar estruturas que possibilitem um modo mais bem informado e rigoroso de produção de conhecimento. (...) Também é importante, contudo, entender sua construção e suas limitações no contexto da pesquisa social contemporânea. A apreciação da complexidade da vida cotidiana e da dificuldade de entendê-la demanda humildade de parte dos pesquisadores. Os bricoleurs entendem que a certeza e a interpretação acabada simplesmente não são possíveis devido a tais complicações (2007, p.47).

Deste modo, minha intenção ao colocar tais problematizações é levantar questionamentos e dúvidas para que não tomemos a bricolagem como um novo (mais um!) modelo da pesquisa acadêmica, como se fosse a melhor e mais eficaz abordagem para operar em todos os casos e contextos de investigação. Creio que a bricolagem em sua teorização ainda está em processo de definição, de se constituir e ser repensada em suas formas de operar e seus alcances em termos de resultados obtidos e experimentados.

Talvez buscar uma definição tão precisa para a bricolagem e de como podemos utilizá-la seja uma contradição já que ela é por si um campo minado de possibilidades a serem exploradas, de modo diferenciado, por cada um que se disponha a conhecê-la. Tantas outras abordagens poderiam ter sido descritas segundo as características que lancei ao longo do texto, e o que fazer com esta constatação ainda não é claro para mim... mas desconfio que seja o caso de, uma vez seduzido por uma abordagem de pesquisa, ir atrás dela, experimentá-la, profaná-la inclusive, até descobrir que efeitos terá sobre si e sobre a investigação que se quer realizar. Assim, estando aqui para apresentá-la, defendo-a (sem negar nossos conflitos e minhas desconfianças) e digo do prazer que é poder brincar de bricolar afetos, indagações, certezas movediças, achados de pesquisa...

Perceber e potencializar as brechas desta abordagem como forma de resistir à obviedade e formatação da pesquisa acadêmica pode ser um dos pontos mais significativos da 
bricolagem, e digo isto não por acreditar que promover este vazamento garantirá uma transformação generalizada nas esferas do meio acadêmico (este não é o objetivo), mas sim em certos contextos, em alguns momentos e circunstâncias, ajudando aos pesquisadores a operar e trabalhar com diferentes ferramentas. A bricolagem certamente concede-nos esta possibilidade, pois confere liberdade de trânsito e escolha ao trabalho do investigador.

Por outro lado, uma vez que a bricolagem fomenta o uso de diferentes métodos e instrumentos, exige-nos em contrapartida um forte poder de argumentação e bases teóricas concisas, no sentido de termos conhecimento sobre o que estamos pesquisando e todos os métodos e perspectivas que estamos bricolando. O bricoleur é concebido "como sendo intelectualmente informado, com ampla leitura e conhecedor de diversos paradigmas de interpretação" (KINCHELOE, 2007, p.41), talvez por isso mesmo seja necessário levar em conta o que é apontado por Kincheloe no decorrer do livro, sobre o fato de que trabalhar com a perspectiva da bricolagem por vezes torna-se um problema ou risco para os pesquisadores mais jovens, iniciantes no campo da pesquisa, devido ao amplo conhecimento e habilidade no uso de certos procedimentos que fazem-se necessários ao pesquisador bricoleur.

Por considerar a complexidade do trabalho desenvolvido dentro da bricolagem, finalizo esta escrita ponderando que muito ainda pode ser realizado por mim enquanto pretensa bricoladora. Sendo assim, posso dizer que é justamente esta multiplicidade, este estado de provisoriedade e esta necessidade de revisão próprios da bricolagem que instigam e mobilizam-me, vez ou outra, a voltar a ela, pesquisando-a conceitualmente, utilizandome de modo fragmentado de suas orientações para seguir bricolando. Como bricoladora sigo catando meus fragmentos: minhas imagens, histórias capturadas que vão se modificando e se transformando em minhas também, filmes que me envolvem e acompanham durante a vida, livros e lugares que vão sendo desdobrados. Todos estes bricolados compondo um mapa, todos atualizados em sua potência de afetar a mim e meus interesses investigativos.

\section{Referências}

DENZIN, N.; LINCOLN, Y. A disciplina e a prática da pesquisa qualitativa. In: DENZIN, N.; LINCOLN, Y. O planejamento da pesquisa qualitativa: teorias e abordagens. Porto Alegre: Artmed, 2006. 
KINCHELOE, Joe; BERRY, Kathleen. Pesquisa em educação: conceituando a bricolagem. Porto Alegre: Artmed, 2007.

KINCHELOE, Joe. O poder da bricolagem: ampliando os métodos de pesquisa. In: KINCHELOE, Joe; BERRY, Kathleen. Pesquisa em educação: conceituando a bricolagem. Porto Alegre: Artmed, 2007.

Redefinindo e interpretando o objeto de estudo. In: KINCHELOE, Joe; BERRY, Kathleen. Pesquisa em educação: conceituando a bricolagem. Porto Alegre: Artmed, 2007.

NUNES, Aline. Notas sobre um professor bricoleur: inventando possíveis para pensar a formação inicial em artes visuais. Revista da FUNDARTE. Montenegro, número 22, 2011. pp.20-31.

SILVA, Tomaz Tadeu da. A filosofia de Deleuze e o currículo. Coleção Desenrêdos, número 1, 2004. Goiânia: Núcleo Editorial FAV-UFG.

\footnotetext{
${ }^{1}$ Doutoranda do Programa de Pós Graduação em Arte e Cultura Visual- PPGACV, linha de pesquisa Culturas da Imagem e Processos de Mediação, pela Universidade Federal de Goiás-UFG. Bolsista pelo Programa de Estágio no Exterior-PDSE, Capes, na Universidade de Barcelona-UB/Espanha, no período de fevereiro de 2013 a fevereiro de 2014. Bolsista Capes 2011-2015. Mestre em Educação pelo Programa de Pós Graduação em Educação- PPGE, da Universidade Federal de Santa Maria-UFSM. Bacharel e Licenciada em Artes Visuais pela mesma instituição. Endereço institucional: Faculdade de Artes Visuais/FAV Universidade Federal de Goiás-UFG Campus Samanbaia (Campus II) - Av. Esperança, s/n, Setor Itatiaia Goiânia-GO 74001-970. Endereço eletrônico: ameline.nr@gmail.com
} 